\title{
Children with abnormal DMSA nuclear scan present a higher risk of recurrent febrile urinary tract infections
}

\author{
Luke Harper $^{1,2} \cdot$ Yan Lefevre ${ }^{2} \cdot$ Xavier Delforge $^{1} \cdot$ David Bourquard $^{3} \cdot$ Cyril Ferdynus $^{4}$
}

Received: 17 August 2017 / Accepted: 5 March 2018 / Published online: 20 March 2018

(c) Children's Hospital, Zhejiang University School of Medicine 2018

The ideal management of a child presenting a first episode of febrile urinary tract infection is still under debate. In the recent guidelines for the diagnosis and management of urinary tract infections (UTI) in children, the American Association of Pediatrics recommend performing a post-UTI sonography, and if there are abnormal findings, a voiding cystourethrogram [1]. This change derives from the understanding that we should be avoiding renal damage rather more than diagnosing reflux, since both surgery and antibiotic prophylaxis are progressively being abandoned for most cases of vesicoureteral reflux (VUR) [2,3]. The most significant event which will bring a child to active management is recurrence of UTI $[4,5]$. It seems therefore more clinically relevant to differentiate between children who will suffer recurrent episodes of UTI and those who will not, rather than to simply identify which children have VUR. We therefore aimed to evaluate if DMSA nuclear scan could reliably identify which children were at risk of presenting a second febrile UTI.

We retrospectively analyzed all children aged between 2 and 24 months, without prenatally diagnosed uropathy, who were admitted to our institution for a first febrile UTI between 2009 and 2013, had a post-urinary tract infection sonography and DMSA nuclear scan, and were followed for at least 24 months. We excluded patients with missing or incomplete data, or lost to follow-up. Febrile UTI was defined as fever $>38^{\circ} \mathrm{C}$ associated with positive urinalysis

Luke Harper

harper_luke@hotmail.com

1 Department of Pediatric Surgery, CHU de La Reunion, La Reunion, France

2 Department of Pediatric Surgery, CHU Pellegrin-Enfants, Bordeaux, France

3 Department of Nuclear Medicine, CHU de La Reunion, La Reunion, France

4 Methodological Support Unit, CHU de La Reunion, La Reunion, France and urine culture $\left(>10^{5} \mathrm{CFU} / \mathrm{mL}\right.$ urine) collected through catheterization in girls, and clean-catch in boys. We noted patient's characteristics, and the results of the DMSA scan performed within 1 month of the acute episode. DMSA scans were categorized as normal, i.e., no scarring or dysplasia, or abnormal, any degree of scarring or dysplasia, functional impairment or atrophy.

After the first febrile UTI, parents were systematically counseled about early diagnosis and having a urinalysis done if their child presented unexplained fever. None were given antibiotic prophylaxis but they were given advice about local hygiene and measures to avoid constipation in their child. All children were followed at least once every 6 months for a minimum of 24 months. The main outcome was recurrence of a second febrile UTI within the first 24 months of follow-up. In case of recurrence, a cystogram was performed, and children were further managed accordingly.

On hundred and seven children were included in our study. There were 49 boys and 58 girls $(45.8 / 54.2 \%)$. None were lost to follow-up, and all relevant data were available for all included patients. Children included did not differ from those who were excluded from the study. The mean age at first febrile UTI was $6.8 \pm 5.4$ months. Twenty-four (22.4\%) children presented abnormal DMSA findings. Six presented asymmetric function without signs of dysplasia or scarring, two had a solitary kidney, and 16 had signs of dysplasia or scarring, of which 6 had asymmetric function. Sixteen $(14.9 \%)$ children presented a recurrence within 24 months, of which ten had an abnormal DMSA scan. Both age and gender were comparable in both groups (with and without recurrence). All boys were uncircumcised. There were significantly more recurrences in the abnormal DMSA group [relative risk $(\mathrm{RR})=5.8 ; 95 \%$ confidence interval $(95 \% \mathrm{CI}) 2.1-15.9$ ] compared to the normal DMSA group. The sensitivity and specificity of DMSA scan to predict which children will present a recurrence of febrile UTI were $62.5 \%$ 
(95\% CI 38.8-86.2\%) and 84.6\% (95\% CI 77.2-92.0\%), respectively. The positive predictive value and negative predictive value were $41.7 \%$ (95\% CI $21.9-61.4 \%$ ) and 92.8\% (95\% CI 87.2-98.3\%), respectively. Of those who presented a recurrence, 14 out of 16 presented VUR on subsequent cystogram.

What this study shows is that children with a normal DMSA scan had a relatively low risk of presenting a recurrence of febrile UTI during their 2-year follow-up, and that those who had an abnormal DMSA scan had a higher risk of presenting a recurrence $(\mathrm{RR}=5.8)$. According to our retrospective series performing a systematic DMSA scan at 1 month, on all children who present a first episode of febrile UTI, will yield around $20 \%$ of abnormal scans, of which $40 \%$ will present a recurrence. The majority will have a normal scan and among these few will present a recurrence. The strength of this study is to have linked abnormal DSMA with risk of recurrent UTI as most previous studies have focused on the relationship between results of various diagnostic tests and the presence or absence of VUR or probability of resolution of VUR [6-16].

We limited our outcome to febrile urinary tract infection as afebrile UTIs are less important clinically. We explained to the parents of the children seen for their first febrile UTI about the benefit of early diagnosis and treatment of febrile UTI and asked them to perform a urine analysis in case of unexplained fever. This message was passed on to their general practitioners. Children were follow-up clinically every 6 months, and all episodes of febrile UTI were recorded. We are fairly confident that we did not miss any significant febrile UTIs and believe that our recurrence rate reflects a reliable rate of recurrence in children without known uropathies, considering only febrile UTIs with reliable urine specimens.

In conclusion, abnormal post-UTI DMSA scan is associated with a higher risk of recurrence of UTI at 24 months.

Author contributions LH contributed to conception or design of the work, data collection, data analysis and interpretation, and drafting of the article. YL contributed to data collection, drafting of the article, and critical revision of the article. XD contributed to data collection. DB contributed to data analysis and interpretation. CF contributed to conception or design of the work, data analysis and interpretation, and critical revision of the article. All authors approved the final version to be published.

\section{Funding None.}

\section{Compliance with ethical standards}

Ethical approval This is an observational study for which no formal Ethics Comittee approval was necessary according to our National Laws on scientific research.
Conflict of interest All authors declare that they have no conflict of interest.

\section{References}

1. Newman TB. The new American Academy of Pediatrics urinary tract infection guideline. Pediatrics. 2011;128:572-5.

2. Jodal U, Smellie JM, Lax H, Hoyer PF. Ten-year results of randomized treatment of children with severe vesicoureteral reflux. Final report of the International Reflux Study in Children. Pediatr Nephrol. 2006;21:785-92.

3. Craig JC, Simpson JM, Williams GJ, Lowe A, Reynolds GJ, McTaggart SJ, et al. Antibiotic prophylaxis and recurrent urinary tract infection in children. $\mathrm{N}$ Engl $\mathrm{J}$ Med. 2009;361:1748-59.

4. Elder JS, Peters CA, Arant BS Jr, Ewalt DH, Hawtrey CE, Hurwitz RS, et al. Pediatric Vesicoureteral Reflux Guidelines Panel summary report on the management of primary vesicoureteral reflux in children. J Urol. 1997;157:1846-51.

5. Woolf AS, Wilcox DT. Understanding primary vesicoureteric reflux and associated nephropathies. Curr Pediatr. 2004; $14: 563-7$.

6. Sheu JN, Wu KH, Chen SM, Tsai JD, Chao YH, Lue KH. Acute 99 mTc DMSA scan predicts dilating vesicoureteral reflux in young children with a first febrile urinary tract infection: a population-based cohort study. Clin Nucl Med. $2013 ; 38: 163-8$.

7. Zhang X, Xu H, Zhou L, Cao Q, Shen Q, Sun L, et al. Accuracy of early DMSA scan for VUR in young children with febrile UTI. Pediatrics. 2014;133:e30-8.

8. Mantadakis E, Vouloumanou EK, Georgantzi GG, Tsalkidis A, Chatzimichael A, Falagas ME. Acute Tc-99m DMSA scan for identifying dilating vesicoureteral reflux in children: a meta-analysis. Pediatrics. 2011;128:e169-79.

9. Harper L, Delforge X, Maurin S, Leroy V, Michel JL, Sauvat F, et al. A novel approach to evaluating the benefit of post-urinary tract infection renal ultrasonography, using decision curve analysis. Pediatr Nephrol. 2016;31:1631-6.

10. Jodal U. The natural history of bacteriuria in childhood. Infect Dis Clin North Am. 1987;1:713-29.

11. Camacho V, Estorch M, Fraga G, Mena E, Fuertes J, Hernández MA, et al. DMSA study performed during febrile urinary tract infection: a predictor of patient outcome? Eur J Nucl Med Mol Imaging. 2004;31:862-6.

12. Preda I, Jodal U, Sixt R, Stokland E, Hansson S. Normal dimercaptosuccinic acid scintigraphy makes voiding cystourethrography unnecessary after urinary tract infection. J Pediatr. 2007;151:5814, 584.e1.

13. Fouzas S, Krikelli E, Vassilakos P, Gkentzi D, Papanastasiou DA, Salakos C. DMSA scan for revealing vesicoureteral reflux in young children with urinary tract infection. Pediatrics. 2010;126:e513-9.

14. Miron D, Daas A, Sakran W, Lumelsky D, Koren A, Horovitz Y. Is omitting post urinary-tract-infection renal ultrasound safe after normal antenatal ultrasound? An observational study. Arch Dis Child. 2007;92:502-4.

15. Preda I, Jodal U, Sixt R, Stokland E, Hansson S. Value of ultrasound in evaluation of infants with first urinary tract infection. $\mathrm{J}$ Urol. 2010;183:1984-8.

16. Mingin GC, Hinds A, Nguyen HT, Baskin LS. Children with a febrile urinary tract infection and a negative radiologic workup: factors predictive of recurrence. Urology. 2004;63:562-5. 